\title{
Pupils' perceptions of safety at school
}

Cowie, H. and Oztug, O.

University of Surrey

Pastoral Care in Education (2008) 26(2):59-67

\section{What makes children feel unsafe at school}

Abstract

The research was carried out in four secondary schools, two with a peer support system (PS) and two without (NPS) and involved a total of 931 pupils, (49.5\% males, and 50.5\% females). Participants were aged between 11 and 15 years of age, mean age 12.8 years. The aim was :to compare the perceptions of safety on the part of pupils in secondary schools with and without a system of peer support in place. The findings provided little evidence that the presence of a peer support system enhanced feelings of safety in the school population. On the positive side, PS pupils were slightly more aware of the value of having other people around as a means of enhancing feelings of safety. They were also less afraid of older pupils indicating that peer supporters may have influenced the attitudes of some older pupils towards younger peers and may have made them friendlier. However; for the PS pupils, toilets and corridors/stairs were less safe for them than for NPS pupils, largely because of the unpleasant actions of the peer group towards them. With specific regard to bullying, there was no difference between PS and NPS. Around one-fifth of both PS and NPS pupils reported that the reason for feeling unsafe was because of bullying. The most common suggestions for making school a better place referred to action against bullying.

Keywords: Peer support; Bullying; School violence; Safety; Active participation of young people; Emotional health and wellbeing

\section{Acknowledgements}


We are grateful to the pupils and teachers in the four schools for enabling this study to take place. We would also like to thank the two anonymous reviewers who provided helpful comments on an earlier version of this paper. This research was generously funded by the Daiwa Anglo-Japanese Foundation.

\section{Introduction}

Children and young people regularly mention relationships within the peer group as the major factor that causes them to feel unsafe at school, with thousands of children each year (around 28,000 in 2006) telephoning ChildLine for advice on bullying either on behalf of themselves or because of their concern for another young person (ChildLine, 2005). In fact, the Children's Commissioner cited bullying as an issue that attracted a bigger response from children and young people than any other aspect of his work (Aynsley-Green, 2006, p. 65). Surveys regularly remind us of the extent of the problem. For example, Oliver and Candappa (2003) found that half of all the primary school children and more than one in four secondary school children in the UK said they had been bullied in the last term.

Since bullying is a subjective experience, it is important to take account of what young people have to say on the matter. To this end, and in line with the UN Convention on the Rights of the Child (UN, 1991) and the Every Child Matters agenda (DfES, 2004; DfES, 2005a; DfES, 2005b; DfES, 2006; OFSTED, 2005), government legislation now requires that schools consult children and young people on issues that concern them. This has resulted in many innovative systems that facilitate the involvement of young people, for example, in school councils, youth parliaments or other democratic systems. One of the most direct, hands-on ways in which to engage pupils' active participation in systems designed to tackle bullying has been the development of peer support systems.

The philosophy of peer support is in harmony with the four core principles underlying the United Nations Convention: non-discrimination; devotion to the best interests of the child; the right to life, survival and development; and respect for the views of the child. The most relevant principle in the present 
paper concerns the process of listening to the voice of the child. In essence, teachers who facilitate peer-led methods encourage young people to show respect for others, to have empathy for their feelings, to act co-operatively and democratically in their groups.

Over $50 \%$ of primary and secondary schools in the UK now have some form of peer support in place in the form of buddying/befriending, mentoring, active listening and conflict resolution (Smith and Samara, 2003). Peer support systems have enormous potential to provide young people with opportunities to address bullying immediately in everyday contexts, and, at a wider level, to be involved in the development of policies to ensure that schools are safe and pleasant places to be. Many teachers who co-ordinate peer support systems encourage peer supporters to play an active part in managing the schemes, and there is evidence that this can be perceived as a significant catalyst for change (Cowie et al, 2002). Peer support systems have changed as young people involved have become more creative and confident in developing the systems in which they have been trained to play a part, for example by making changes in the logistics of peer support, and developing use of the internet and e-mail support (Cartwright, 2005; Cowie \& Hutson, 2005; Hutson \& Cowie, in press).

There is no doubt that peer supporters benefit greatly from the training; those whom they help directly also report that their intervention is helpful (Cowie et al, 2002; Lane-Garon, Ybarra-Merlo, Zajac \& Vierra, 2005; Naylor \& Cowie, 1999; Smith and Watson, 2004). But does peer support actually reduce bullying and does it therefore make schools safer?

Research findings indicate a subjective impression that bullying rates are reduced by the activity of a peer support system. Selected teachers, often the people responsible for the running of the system, can often be euphoric about the impact of a peer support service on their schools. One teacher from the Mental Health Foundation project on peer support concluded that the presence of a peer support system led to 'enrichment of the life of the school' (quoted in Scherer-Thompson, 2002, p. 11). A deputy-head teacher on the 
ChildLine peer support project (quoted in ChildLine, 2005, p. 2) claimed that, as a result of peer support, 'bullying rates have been drastically reduced, our exam rates are better than they were five years ago, and attendance figures are the best we have ever had, up from $89 \%$ to $95 \%$ now. Kids come to a school when they're happy, and they don't come when they're not.'

The ChildLine report on peer support (ChildLine, 2005, p. 3) made dramatic claims about the impact that peer support had on bullying and its role in creating safer schools:

'On a school-wide level, peer support can radically improve the atmosphere of a school, allowing pupils to feel safer and more supported, while simultaneously freeing teachers of the unwelcome task of having to be disciplinarians first and educators second.'

Some research confirms these views. For example, Lane-Garon and Richardson (2003) studied the impact of a peer mediation scheme on school climate in a sample of 300 elementary school pupils. Both mediators and non-mediators perceived the school climate to be safer than had been reported in the year prior to the introduction of the peer mediation scheme. However, it is important to note that in this scheme large numbers of pupils received the training and this, according to the researchers, played an important part in enhancing the impact on perceptions of safety. In confirmation of this hypothesis, Lane-Garon et al (2005) compared 35 children trained as mediators with matched controls who had not been trained. One year after the introduction of the Mediator Mentors Program, mediators demonstrated significantly higher gains in measures of social-cognitive development when compared to non-mediators. Additionally, the researchers found that there appeared to be less yelling and hitting in the families of mediators in comparison to non-mediators, suggesting that the children were practising their mediation skills at home. 
However, in contrast to the positive endorsements of peer support, some researchers have sounded a note of caution. Naylor and Cowie (1999) found that the incidence of bullying in their sample of 51 schools with an established peer support system was similar to that reported in other schools (without a peer support system) at the time, e.g. Whitney and Smith (1993). They concluded that the presence of a peer support system in itself does not appear to bring about a reduction of bullying but they also noted that the majority of peer supporters, users and potential users of the systems and teachers in their schools believed that bullying had decreased, even though the 'objective' evidence obtained from the questionnaires did not confirm this. Cowie and Olafsson (2001) actually found some increase in bullying three terms after the introduction of a peer support system, although also increased rates of reporting by those who were bullied. This was a very atypical school, but it does illustrate that positive outcomes at the broader school level cannot be taken for granted.

In their evaluation of the CHIPS peer support intervention, Smith and Watson (2004) identified a range of perspectives on the effectiveness of peer support in creating safer schools and, in particular, on reducing rates of bullying. Many staff and pupils believed that there were positive effects on general levels of school bullying or peer relationships, but many were also unsure. The degree to which the peer support strategy had been integrated into the whole school policy or 'ethos' was often a contributing factor to its success, suggesting that for it to succeed the peer support system needed to be a coherent part of the whole-school strategy for counteracting bullying. Schools that made pupils aware of the scheme, through the use of assemblies, newsletters, posters and presentations, often found that the scheme became more accepted, and the peer mentors earned respect and credibility from fellow pupils. But the researchers also observed that it was rare to find any interaction between schools in terms of planned sharing of expertise, experience and examples of good practice. None of the schools offered mentors the opportunity to exchange ideas with pupils from other schools. Furthermore, there was little continuity between primary and secondary sectors, with secondary schools failing to capitalise on the skills of peer mentors moving up from primary education. Some of the peer supporters complained that teachers failed to give them enough responsibility and too often under-valued the skills that they had learned in training. 
We felt, in planning this research, that it was timely to carry out a comparison of schools with and schools without peer support in order to see if there were indeed positive outcomes with regard to pupils' perceptions of safety at school. The present research reports on the analysis of qualitative data from a survey carried out with 931 pupils in four secondary schools, two with peer support and two without. The quantitative analysis (Cowie, Hutson, Oztug \& Myers, 2008) revealed very little difference between pupil perceptions of safety in schools with and schools without a peer support system in place. In fact, older pupils in the schools without peer support responded that they felt safer than pupils in schools with a peer support system in toilets and lessons. However, within the peer support schools there were significant differences in perceptions of safety between the substantial minority of pupils who were unaware that their school had a peer support system and those who were aware of it. The pupils who were aware felt safer in lessons, perceived school as a friendlier place to be, worried significantly less about being bullied in comparison with those who were unaware. They were also much more likely to tell someone when bad things happened at school. The researchers argued that unless a peer support system is widely disseminated as part of the whole-school strategy to counteract bullying and violence, it will fail to reach a proportion of pupils who may well be those in particular need of help. The present study was concerned to find out what were the particular safety issues that concerned the pupils in the four schools and what were their suggestions for making changes within the school that would make them feel more secure. We were also interested to discover whether the suggestions for improvement were ones that peer supporters had the potential to put into practice.

\section{Method}

\section{Participants}

The research was carried out in four secondary schools in a small rural town, each with a well-organised pastoral care system and an active anti-bullying policy. The study involved a total of 931 pupils, (49.5\% males, 50.5\% females). Participants were aged between 11 and 15 years of age. 
Two schools that already had established peer support schemes were matched with two schools which had yet to commence their peer support training. All other demographic variables were matched to the best of our ability through examining the census data for the schools (OFSTED Inspection Reports). There appeared to be nothing of any significance in the variations that could have led to bias in the results.

\section{Instruments}

The survey was carried out using the School Climate Questionnaire (Myers \& Hutson, unpublished) that consisted of three open ended questions 'Where do you feel least safe and why?', 'Where do you feel most safe and why', and 'What are your suggestions for making the school a better place?'. The present paper aims to address participants' responses to these questions.

\section{Procedure}

The questionnaire was administered during a PSHE lesson by the classroom teachers. We provided each school with the required number of questionnaires and a script to read out to each class. Once the questionnaires were completed anonymously the schools posted them to the research team at the University of Surrey in pre-paid envelopes.

Specific instructions were provided to the teachers, and anonymity of each participant was assured to each class. Informed consent was obtained from schools, pupils and parents. The questionnaires were personally delivered to the Head Teachers by members of the research team, and personally collected, so that any issues could be resolved face to face. The schools were asked to participate and agreed in writing after receiving an information pack. All parents of participating pupils were sent a letter the week before and information pack about the research using an opt-out format. On the day the research took place, pupils were again reminded that they could withdraw at any time and that participation was entirely voluntary. Each pupil also received an information pack about the research. In the event, no pupils or parents opted out of the research. The researchers agreed to feedback the findings to each individual school. 


\section{Qualitative analysis}

All responses to the questions were transferred to spreadsheet software Microsoft Office Excel. The data were coded by examining each response, question by question, The questions 'Where do you feel least safe and why?' and 'Where do you feel most safe and why' were coded under the two themes of 'places where pupils felt safe or unsafe' and 'reasons for feeling safe or unsafe'. The codes obtained as a result of the analysis were then arranged into logical categories.

The responses to the final question 'what are your suggestions for making the school a better place?' were initially reviewed for identification of the major themes in the data. The responses were then coded by breaking down the major themes into sub-themes wherever possible.

\section{Results}

In answer to the question 'Where do you feel most safe?' the most frequent response referred to feeling safe in the classroom, with slightly more pupils in peer support schools (PS) (22.4\%) than non-peer support schools (NPS) $(18.5 \%)$ stating that they felt safest in lessons with a teacher present (Figure $1)$.

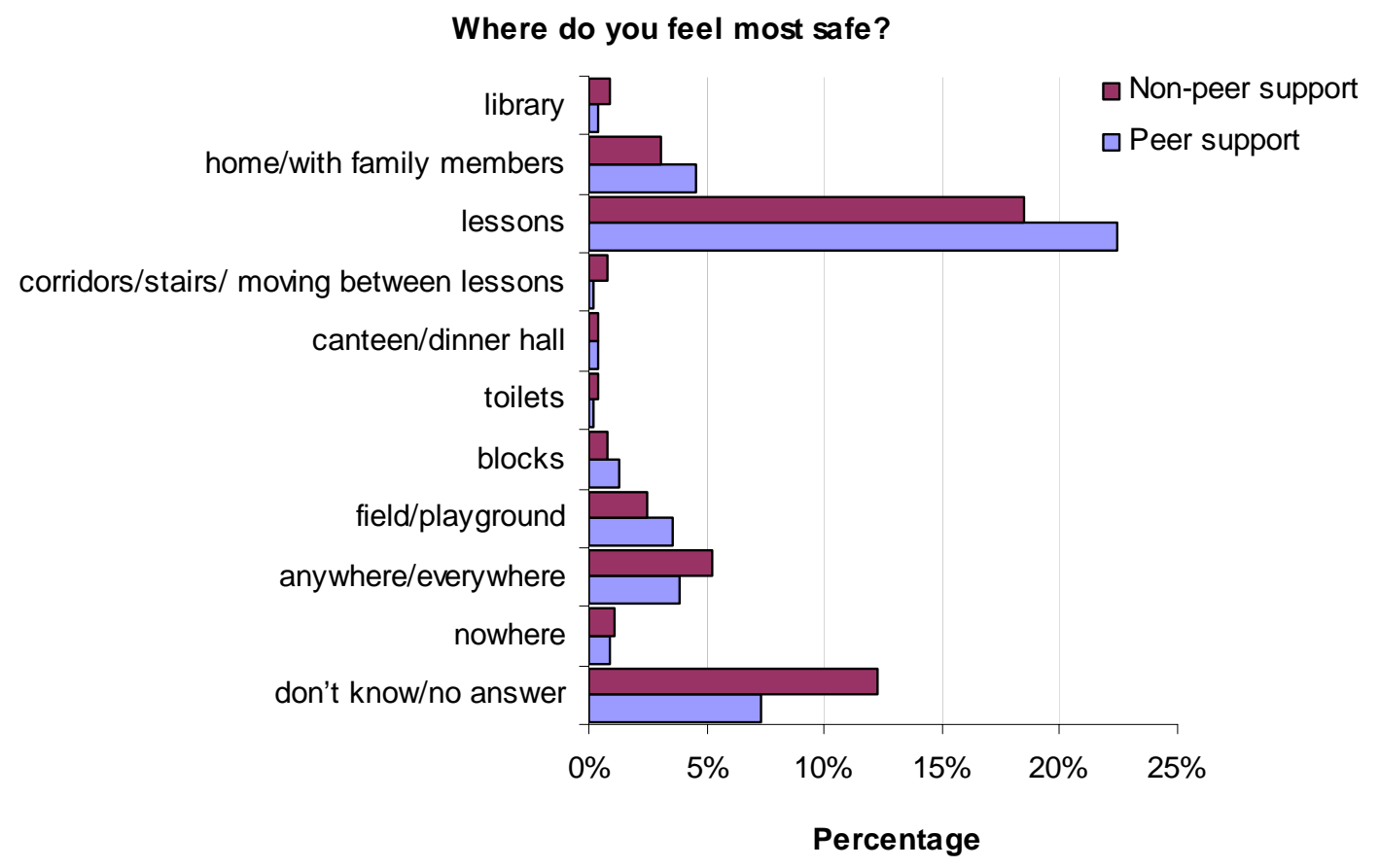


Figure 1: Graphical representation of places where pupils felt most safe at school

The most common explanation for feeling safe referred to the support or presence of other people, with slightly more PS (62.7\%) than NPS (56.1\%) citing the presence of friends, teachers or others (Figure 2).

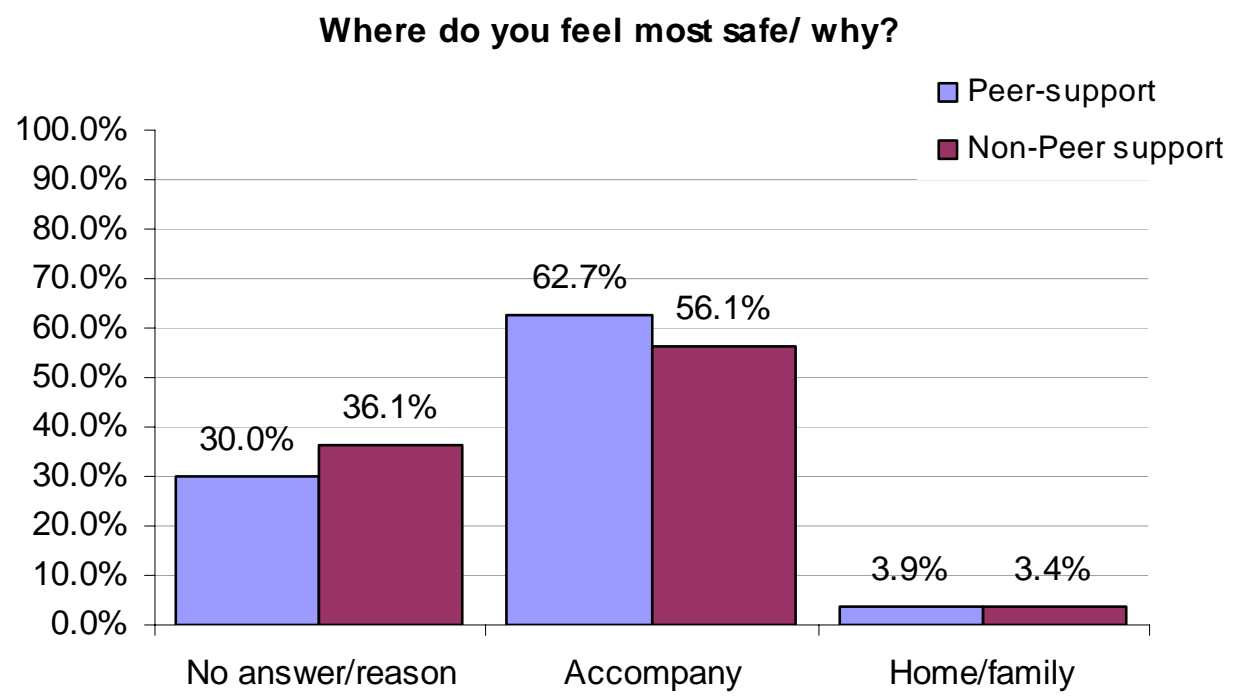

Figure 2: Graphical representation of reasons why PS and NPS pupils felt most safe at school

In answer to the question 'Where do you feel most unsafe and why?', the most unsafe places reported by the whole sample were play areas (playground and field) (20.8\%), toilets (15.3\%), corridors/stair and other places where there was movement between lessons (9.5\%), and journeys to and from school (7.7\%) (Table 1).

Table 1: Frequency and percentages of pupils who felt unsafe with respect to the places in and outside of school 


\begin{tabular}{|l|c|c|c|c|c|c|}
\multicolumn{2}{c|}{} & \multicolumn{2}{c|}{ Peer support } & \multicolumn{2}{c|}{ Non-peer support } & \multicolumn{2}{c|}{ Overall } \\
\cline { 2 - 6 } \multicolumn{1}{c|}{} & $\boldsymbol{N}$ & $\%$ & $\boldsymbol{N}$ & $\%$ & $\boldsymbol{N}$ & $\%$ \\
\hline don't know/no answer & 109 & $11.7 \%$ & 127 & $13.6 \%$ & 236 & $25.3 \%$ \\
\hline nowhere & 31 & $3.3 \%$ & 52 & $5.6 \%$ & 83 & $8.9 \%$ \\
\hline anywhere/everywhere & 14 & $1.5 \%$ & 7 & $0.8 \%$ & 21 & $2.3 \%$ \\
\hline field/playground & 100 & $10.7 \%$ & 94 & $10.1 \%$ & 194 & $20.8 \%$ \\
\hline blocks & 3 & $0.3 \%$ & 11 & $1.2 \%$ & 14 & $1.5 \%$ \\
\hline toilets & 90 & $9.7 \%$ & 53 & $5.7 \%$ & 143 & $15.3 \%$ \\
\hline canteen/dinner hall & 5 & $0.5 \%$ & 11 & $1.2 \%$ & 16 & $1.7 \%$ \\
\hline corridors/stairs/moving between lessons & 55 & $5.9 \%$ & 34 & $3.6 \%$ & 89 & $9.5 \%$ \\
\hline lessons & 9 & $1.0 \%$ & 11 & $1.2 \%$ & 20 & $2.1 \%$ \\
\hline outside school/walking home/ bus/other & 29 & $3.1 \%$ & 43 & $4.6 \%$ & 72 & $7.7 \%$ \\
\hline with seniors/older pupils & 3 & $0.3 \%$ & 9 & $1.0 \%$ & 12 & $1.3 \%$ \\
\hline with tutor/teacher & 6 & $0.6 \%$ & 0 & $0.0 \%$ & 6 & $0.6 \%$ \\
\hline changing rooms/lockers & 2 & $0.2 \%$ & 1 & $0.1 \%$ & 3 & $0.3 \%$ \\
\hline other & 10 & $1.1 \%$ & 10 & $1.1 \%$ & 20 & $2.1 \%$ \\
\hline
\end{tabular}

There were no differences between PS (10.7\%) and NPS (10.1\%) with regard to play areas and only very small differences concerning journeys to and from school (PS $=3.1 \%$; NPS $=4.6 \%)$. But substantially more PS $(9.7 \%)$ felt unsafe in the toilets than NPS (5.7\%) and in corridors/stairs (PS=5.9\%; NPS=3.6\%) (see Table 2.) The most frequently given reasons for feeling unsafe concerned bullying ( $P S=22.1 \%$; NPS=24.5\%). Interestingly, pupils from PS (5.6\%) schools felt less worried about older peers than pupils from NPS (9.5\%). At the same time, they worried more about lack of protection from intruders and strangers on school premises (PS=10.3\%; NPS=4.1\%). It is also worth noting that a comparatively high percentage of both PS and NPS had no answer to the question about why (35\%) or where (25\%) they felt unsafe in school. (Table 2)

Table 2: Frequency and percentages of pupils who felt unsafe at school with respect to the given reasons

\begin{tabular}{|l|c|c|c|c|c|c|}
\cline { 2 - 5 } \multicolumn{1}{c|}{} & \multicolumn{2}{c|}{ Peer-support } & \multicolumn{2}{c|}{ Non-Peer support } & \multicolumn{2}{c|}{} \\
\hline Categories & Frequency & Percentage & Frequency & Percentage & Total & Percentage \\
\hline No answer/reason & 164 & $35.1 \%$ & 163 & $35.1 \%$ & 327 & $35.1 \%$ \\
\hline Bullies/bullied & 103 & $22.1 \%$ & 114 & $24.5 \%$ & 217 & $23.3 \%$ \\
\hline Lack of protection & 48 & $10.3 \%$ & 19 & $4.1 \%$ & 67 & $7.2 \%$ \\
\hline Older pupils & 26 & $5.6 \%$ & 44 & $9.5 \%$ & 70 & $7.5 \%$ \\
\hline Crowd & 12 & $2.6 \%$ & 10 & $2.2 \%$ & 22 & $2.4 \%$ \\
\hline Smoke/smokers & 33 & $7.1 \%$ & 4 & $0.9 \%$ & 37 & $4.0 \%$ \\
\hline Chavs & 12 & $2.6 \%$ & 0 & $0.0 \%$ & 12 & $1.3 \%$ \\
\hline Outside school & 20 & $4.3 \%$ & 28 & $6.0 \%$ & 48 & $5.2 \%$ \\
\hline
\end{tabular}


The most frequent suggestions for making school a better place referred to reducing or stopping the bullying (PS=21.8\%; NPS=22.4\%) and improving and varying activities in school (PS=10.3\%; NPS=14.4\%). There were also requests to improve the school facilities (PS=9.2\%; NPS=7.3\%) with a particular emphasis in the PS schools on improving the toilet areas. Slightly more PS (3.2\%) than NPS (0.2\%) asked for action against smoking and this was most likely connected with their reports of smokers and 'chavs' in toilet areas whose presence was menacing or threatening. ('Chav' is a derogatory slang term in popular usage throughout the UK. It refers to a subculture stereotype of a person who is uneducated, uncultured and prone to antisocial or immoral behaviour.)

\section{Discussion}

The findings provided little evidence that the presence of a peer support system enhanced feelings of safety in the school population. On the positive side, PS pupils were slightly more aware of the value of having other people around as a means of enhancing feelings of safety. They were also less afraid of older pupils indicating that peer supporters may have influenced the attitudes of some older pupils towards younger peers and may have made them friendlier. However; for the PS pupils, toilets and corridors/stairs were less safe for them than for NPS pupils, largely because of the unpleasant actions of the peer group towards them. With specific regard to bullying, there was no difference between PS and NPS. Around one-fifth of both PS and NPS pupils reported that the reason for feeling unsafe was because of bullying. The most common suggestions for making school a better place referred to action against bullying, with more PS mentioning people who smoke and unpleasant people or 'chavs'.

Given the continued prevalence of bullying and its impact on health and wellbeing, it is essential that schools use to the optimum effect the skills that peer supporters learn in training. They also need to pay much more than lipservice to the active involvement of young people in resolving issues that directly affect them, such as bullying, in order to safeguard children and young people. The present study indicated a worrying gap between the willingness 
of the peer supporters to help reduce bullying and the real anxieties of the school population about issues that made them feel unsafe. Certain places such as toilets presented everyday challenges to many pupils yet the peer support system did not appear to have developed procedures to address the problem. Furthermore, there appeared to be no system for the peer supporters to carry out any form of pupil evaluation of the service that they offered. Anti-bullying policies should routinely involve children and young people in developing solutions to bullying and monitoring the effectiveness of interventions such as peer support. It would also be beneficial to find out more about the relatively large proportion of pupils who felt unsafe but simply had no answer to the questions about why or where they felt unsafe. We recommend that not only should peer supporters carry out regular evaluations of the service but also facilitate representative focus groups of other young people in order to brain storm ideas for future improvements.

There may also be an argument for the training to be carried out with a much wider population of young people. Research into peer mediation programmes indicates that training only a small number of mediators is not preventative of violence or favourable to optimum developmental outcomes and, in fact, there is evidence that as the number of trained mediators grows in proportion to the school population so school climate effects are more likely (Lane-Garon \& Richardson, 2003). One suggestion that came from 4 pupils in one of the PS schools in the present study was to offer training to the bullies.

We end with a list of recommendations that those involved in the running of peer support systems and in the training of peer supporters may like to consider:

- Carry out regular surveys and focus groups to discover if they are meeting the needs of the school population

- Training should incorporate peer research skills

- Be aware of the diverse places in which bullying takes place

- Listen to the peer group 
- Gather regular feedback on the impact of their service on the school population

- Patrol areas of particular risk, such as toilets, play areas, corridors;

- Identify priority issues that need to be addressed

- Learn how to play an active participant role in challenging bullying

- Play an active role in the development of the school anti bullying policy and practice

\section{References}

Aynsley-Green, A. (2006) Bullying Today. London: Office of the Children's Commissioner.

Cartwright, N (2005). Setting up and sustaining peer support systems in a range of schools over 20 years. Pastoral Care in Education, 23, 45-50.

ChildLine (2005) Every School Should Have One: How Peer Support Schemes Make Schools Better. London: ChildLine.

http://www.childline.org.uk/pdfs/peersupportreport.pdf (accessed June 2007)

Cowie, H. and Hutson, N. (2005). Peer support: a strategy to help bystanders challenge school bullying. Pastoral Care in Education, 23, 40-44.

Cowie, H., Hutson, N., Oztug, O. and Myers, C. (2008) The impact of peer support schemes on pupils' perceptions of bullying, aggression and safety at school, Emotional and Behavioural Difficulties, 13(1): 63-71.

Cowie, H., Naylor, P., Talamelli, L., Chauhan, P. and Smith, P. K. (2002). Knowledge, use of and attitudes towards peer support. Journal of Adolescence, 25, 5, 453-467.

Cowie, H. and Olafsson, R. (2001) The role of peer support in helping the victims of bullying in a school with high levels of aggression, School Psychology International, 21, 1, 79-95.

Hutson, N. \& Cowie, H. (in press) Setting up an e-mail peer support service, Pastoral Care in Education

DfES (2004). Safeguarding Children in Education. DfES.

DfES (2005a). Secondary National Strategy for School Improvement 20052006. DfES. 
DfES, (2005b). Excellence and Enjoyment: social and emotional aspects of learning. DfES.

DfES. (2006). Bullying Don't Suffer in Silence. An anti-bullying pack for schools ( $3^{\text {rd }}$ rev. ed). DfES.

Lane-Garon, P. \& Richardson, T. (2003) Mediator mentors: improving school climate - nurturing student disposition, Conflict Resolution Quarterly, 21:1 47-69.

Lane-Garon, P., Ybarra-Merlo, M., Zajac, J. D. \& Vierra, T. (2005) Mediators and mentors: partners in conflct resolution and peace education, Journal of Peace Education, 2, 2, 183-193.

Naylor, P\& Cowie, H. (1999). The effectiveness of peer support systems in challenging school bullying: the perspectives and experiences of teachers and pupils. Journal of Adolescence, 22, 467-479.

OFSTED (2005). Every Child Matters: Framework for the Inspection of Children's Services. OFSTED

Oliver, C., and Candappa, M. (2003). Tackling Bullying: Listening to the views of children and young people. Research report RR400, DfES publications.

Scherer-Thompson, J. (2002) Peer Support Manual. London: Mental Health Foundation.

Smith, P.K. \& Samara, M. (2003) Evaluation of the DfES Anti-Bullying Pack. Research Brief No. RBX06-03 (DfES, London).

Smith, P.K. \& Watson, D. (2004) Evaluation of the CHIPS (ChildLine in Partnership with Schools) programme. Research report RR570, DfES publications, PO Box 5050, Sherwood Park, Annesley, Nottingham NG15 0DJ.

United Nations (1991) United Nations Convention on the Rights of the Child (Innocenti Studies, Florence: UNICEF). 